\title{
Treatment of Fibromyalgia with Antidepressants
}

\author{
A Meta-analysis \\ Patrick G. O'Malley, MD, MPH, Erin Balden, MD, MPH, Glen Tomkins, MD, MPH, \\ James Santoro, MD, MPH, Kurt Kroenke, MD, Jeffrey L. Jackson, MD, MPH
}

\begin{abstract}
BACKGROUND: Fibromyalgia is a common, poorly understood musculoskeletal pain syndrome with limited therapeutic options.
\end{abstract}

OBJECTIVE: To systematically review the efficacy of antidepressants in the treatment of fibromyalgia and examine whether this effect was independent of depression.

DESIGN: Meta-analysis of English-language, randomized, placebo-controlled trials. Studies were obtained from searching MEDLINE, EMBASE, and PSYCLIT (1966-1999), the Cochrane Library, unpublished literature, and bibliographies. We performed independent duplicate review of each study for both inclusion and data extraction.

MAIN RESULTS: Sixteen randomized, placebo-controlled trials were identified, of which 13 were appropriate for data extraction. There were 3 classes of antidepressants evaluated: tricyclics (9 trials), selective serotonin reuptake inhibitors (3 trials), and S-adenosylmethionine ( 2 trials). Overall, the quality of the studies was good (mean score 5.6, scale 0-8). The odds ratio for improvement with therapy was 4.2 (95\% confidence interval $[95 \% \mathrm{CI}], 2.6$ to 6.8$)$. The pooled risk difference for these studies was 0.25 (95\% CI, 0.16 to 0.34 ), which calculates to 4 (95\% CI, 2.9 to 6.3) individuals needing treatment for 1 patient to experience symptom improvement. When the effect on individual symptoms was combined, antidepressants improved sleep, fatigue, pain, and well-being, but not trigger points. In the 5 studies where there was adequate assessment for an effect independent of depression, only 1 study found a correlation between symptom improvement and depression scores. Outcomes were not affected by class of agent or quality score using meta-regression.

Received from the Division of General Internal Medicine, Walter Reed Army Medical Center Washington, DC (PGO, EB, GT); Uniformed Services University of the Health Sciences, Bethesda, Md (JLJ, PGO); William Beaumont Army Medical Center, El Paso, Tex (JS); and the Regenstrief Institute for Health Care, Indiana University School of Medicine, Indianapolis, Ind (KK).

The opinions or assertions herein are the private views of the authors and are not to be construed as reflecting the views of the Department of the Army or the Department of Defense.

Address correspondence to Dr. O'Malley: Assistant Professor of Medicine, Department of Medicine (EDP), Uniformed Services University of the Health Sciences, Bethesda, MD 20814.
CONCLUSION: Antidepressants are efficacious in treating many of the symptoms of fibromyalgia. Patients were more than 4 times as likely to report overall improvement, and reported moderate reductions in individual symptoms, particularly pain. Whether this effect is independent of depression needs further study.

J GEN INTERN MED 2000:15;659-666.

$\mathbf{F}$ ibromyalgia is a syndrome of chronic musculoskeletal pain that is commonly diagnosed, poorly understood, and difficult to treat. Fibromyalgia accounts for 15\% of outpatient rheumatology visits and $5 \%$ of general medicine visits. ${ }^{1}$ It is more common in females and the incidence increases with age. ${ }^{2}$ Typical symptoms include chronic musculoskeletal pain and stiffness, tenderness over specific trigger points, fatigue, and disrupted sleep.

The role of psychological factors in the pathogenesis of fibromyalgia is controversial. Depressive symptoms are often present, but it has been difficult to determine if depressive disorders are a primary cause of fibromyalgia, or a reaction to the debilitating symptoms of this disease. It has been reported that over half of patients diagnosed with fibromyalgia have a lifetime history of depression, although active depression is present in only one third..$^{3,4}$ Conversely, it has also been reported that the prevalence of depression is no higher in fibromyalgia than in rheumatoid arthritis or normal controls. 5,6

While antidepressant therapy has been demonstrated to be efficacious in pain syndromes for which there is a well-established understanding of the pathophysiology, ${ }^{7-9}$ the evidence regarding efficacy of antidepressants in other types of physical symptom syndromes such as fibromyalgia has not been critically reviewed.

The purpose of this paper is to systematically review the literature on the efficacy of antidepressive agents in the treatment of fibromyalgia and assess whether any demonstrated efficacy is independent of an effect on depression.

\section{METHODS}

We searched MEDLINE (January 1966-June 1999), PSYCLIT (1974-1998) and EMBASE (1974-1998) using the following text and key words (all languages, limited to "human"): anti- 
depressive agents, serotonin uptake inhibitors, monoamine oxidase inhibitors, amoxapine, clomipramine, tramipramine, desipramine, doxepin, imipramine, amitriptyline, maprotiline, nortriptyline, protriptyline, trazodone, nefazodone, fluoxetine, fluvoxamine, paroxetine, sertraline, femoxetine, venlafaxine, bupropion, citalopram, mianserin, pizotyline, pizotifen, and fibromyalgia, fibrositis, fibromyositis. We used the Cochrane library, ${ }^{10}$ searching the clinical trials registry for randomized trials, and the Cochrane Database of Systematic Reviews (DARE) for systematic reviews. We also searched Federal Research in Progress (FEDRIP) to identify unpublished literature. We searched the references of reviewed articles for additional articles missed by the computerized database search. All primary and review articles, as well as their references, were reviewed independently in duplicate.

Studies were screened for inclusion (through review of the published article) based on the following criteria: randomization of treatment, placebo control, at least 1 group receiving an antidepressant, and report of measurable outcomes. Each study was reviewed in duplicate for inclusion with substantial interrater agreement $(\kappa=0.70)$. Disagreements were arbitrated by consensus.

The quality of each included trial was assessed using a 6 -item instrument developed and validated by Jadad. ${ }^{11}$ The 6 items in this scale include description and appropriateness of randomization, adequacy of blinding, description of withdrawals and dropouts, appropriateness of statistical analysis, clear description of inclusion and exclusion criteria and a method to assess adverse treatment effects. Study quality was assessed independently in duplicate, with substantial interrater agreement (intraclass $r=$ .84). Disagreements were arbitrated by consensus.

Abstracted data included setting, country of origin, treatment characteristics (dose, duration, follow-up), demographics, number of participants enrolled, assessment of comorbid psychiatric disease, follow-up losses, adverse effects, and outcomes. Outcomes were extracted as either dichotomous or continuous variables (or both), depending on how they were reported in the studies.

All analyses were done using STATA, module "metan" (STATA Corp., College Station, Tex). Assessment for publication bias was done using the methods of Egger, ${ }^{12}$ and heterogeneity of effect size was assessed using the methods of Mantel-Haenszel. A random effects model using the method of DerSimonian and Laird ${ }^{13}$ was used to calculate the summary odds ratio, risk difference, summary mean symptom scores, and standardized mean differences. Analysis of the continuous outcomes involved comparing standardized differences in means between control and treatment groups. This approach is especially appropriate when studies measure the same concept but use a variety of continuous scales. By standardization, study results are transformed to a common scale (standard deviation units) that facilitates pooling. Additionally, we combined continuous data using the original units in those studies where similar rating scales were used.

A test for the relative influence of each individual study on the results was determined by sequentially dropping individual studies and calculating the resulting summary measures. The effect of year of publication, study design (parallel vs crossover), quality score, and drug class was assessed using meta-regression.

\section{RESULTS}

The literature search produced 41 citations involving antidepressants and fibromyalgia, 16 of which met initial inclusion criteria. ${ }^{14-29}$ of the 25 excluded articles, 9 were review articles, 5 did not include an antidepressant arm, 4 were not randomized trials, 2 were case reports, 2 were letters, 2 did not include a placebo arm, and 1 included multiple organic rheumatologic syndromes. On more detailed review of the 16 initially included articles, 3 were excluded from the synthesis of data for the following reasons: 2 had no extractable data, ${ }^{18,28}$ and 1 was a report of 23 N-of- 1 trials. ${ }^{19}$

\section{Study Quality}

The remaining 13 randomized, placebo-controlled trials had consistently high quality scores (mean 5.6, range 0-8). The mean sample size was 54 patients (range 17-208), and the mean trial duration was 8.1 weeks (range 3-24). Particular problems with the studies (see Table 2) included no statement on the method of randomization, ${ }^{14,17,20,21,23-27,29}$ no intention-to-treat analysis, ${ }^{21,22,24-27,29}$ inadequate assurance that blinding was effective, ${ }^{15,24,27}$ no method of assessing side effects, ${ }^{16,20,21,26,27}$ and large losses to follow-up $(>20 \%) .{ }^{15,21,22,24,25,29}$

\section{Qualitative Synthesis}

Details of individual studies are presented in Tables 1 and 2. Overall, the studies were remarkably similar in their diagnostic inclusion criteria, assessment of depression using validated tools (when measured), and outcomes measured.

The studies used very similar if not identical inclusion criteria for the diagnosis of fibromyalgia. Of the 13 studies with extractable data that were then included in the quantitative synthesis, 11 used either the American College of Rheumatology (ACR) criteria $(n=8)$ or the Smythe criteria $(n=3) .{ }^{30}$ These criteria differ only by a requirement of a sleep disturbance in the Smythe criteria. However, given the wide prevalence of sleep disturbance among the populations of the other studies, this amounts to no effective difference in character of illness among the study populations. Both studies which did not use the ACR or Smythe criteria were older studies, ${ }^{21,27}$ but were remarkably similar in their inclusion criteria to the other criteria (Table 1).

Outcomes assessments were similar across studies with extractable data, all using self-reported visual analog scales for fatigue, pain, well-being, and sleep, and physician assessments for number and severity of trigger points.

Based on the qualitative homogeneity of diagnosis, 
Table 1. Sixteen Randomized, Placebo-Controlled Trials of Antidepressants in Fibromyalgia

\begin{tabular}{|c|c|c|c|c|c|}
\hline $\begin{array}{l}\text { Study, Year, } \\
\text { Country }\end{array}$ & $\begin{array}{l}\text { Inclusion } \\
\text { Criteria }\end{array}$ & $N$ & $\begin{array}{l}\text { Treatment } \\
\text { Groups }\end{array}$ & $\begin{array}{l}\text { Design } \\
\text { Duration }\end{array}$ & $\begin{array}{l}\text { Mean Age } \\
\text { (SD or range) } \\
\% \text { Women }\end{array}$ \\
\hline & Smythe* & 32 & Placebo & 9 weeks & 92 \\
\hline $\begin{array}{l}\text { Goldenberg, } 1986 \\
\text { USA }\end{array}$ & $\geq 3$ mos widespread pain & 16 & $\begin{array}{l}\text { Amitriptyline } \\
\text { (25 mg q hs) }\end{array}$ & Parallel & $43.8(21-69)$ \\
\hline \multirow[t]{3}{*}{$\begin{array}{l}\text { Bibolotti, } 1986 \\
\text { Italy }\end{array}$} & Extra-articular pain & 37 & $\begin{array}{l}\text { Amitriptyline } \\
\text { (50 mg) }\end{array}$ & Crossover & $38.5(27-54)$ \\
\hline & $\begin{array}{l}\text { Variability in pain, } \\
\text { intensity, and duration }\end{array}$ & & Chlorimipramine & $\begin{array}{l}3 \text { weeks each } \\
\text { with no washout }\end{array}$ & 100 \\
\hline & $\begin{array}{l}\text { Modulated by weather } \\
\text { Trigger points } \\
\text { Muscle hypertone }\end{array}$ & & Placebo & & \\
\hline & $\begin{array}{l}3 \text { tender pts }+5 \text { minor } \\
\text { criteria or } 5 \text { tender pts } \\
+3 \text { minor ciriteria }\end{array}$ & & Placebo & $\begin{array}{l}3 \text { weeks with } \\
2 \text {-week washout }\end{array}$ & \\
\hline \multirow[t]{2}{*}{$\begin{array}{l}\text { Scudds, } 1989 \\
\text { Canada }\end{array}$} & Smythe & 36 & $\begin{array}{l}\text { Amitriptyline } \\
\text { (50 mg ) }\end{array}$ & Crossover & $39.9(24-59)$ \\
\hline & & & Placebo & $\begin{array}{l}4 \text { weeks with } \\
2 \text {-week washout }\end{array}$ & 89 \\
\hline \multirow[t]{2}{*}{$\begin{array}{l}\text { Jaeschke, } 1991 \\
\text { Canada }\end{array}$} & "Conventional criteria" & 23 & $\begin{array}{l}\text { Amitriptyline } \\
\text { (5-50 mg) }\end{array}$ & N-of- 1 & $55(43-75)$ \\
\hline & Smythe, predominantly & & Placebo & 2 weeks with no washout & Gender not given \\
\hline $\begin{array}{l}\text { Jacobsen, } 1991 \\
\text { Denmark }\end{array}$ & Smythe & 22 & $\begin{array}{l}\text { S-adenosylmethionine } \\
\text { (800 mg qd) }\end{array}$ & Parallel & $49.4(41-57)$ \\
\hline & & 21 & Placebo & 6 weeks & 100 \\
\hline \multirow[t]{2}{*}{$\begin{array}{l}\text { Carrette, } 1995 \\
\text { Canada }\end{array}$} & ACR & 22 & $\begin{array}{l}\text { Amitriptyline } \\
\text { (25 mg qhs) }\end{array}$ & Crossover & $43.8( \pm 8.0)$ \\
\hline & & & Placebo & $\begin{array}{l}8 \text { weeks each } \\
\text { with no washout }\end{array}$ & 96 \\
\hline \multirow[t]{2}{*}{$\begin{array}{l}\text { Norregaard, } 1995 \\
\text { Denmark }\end{array}$} & $\mathrm{ACR}$ & 22 & $\begin{array}{l}\text { Citalopram } \\
\text { (20 mg) }\end{array}$ & Parallel & $49( \pm 9)$ \\
\hline & & 21 & Placebo & 8 weeks & Gender not reported \\
\hline \multirow[t]{2}{*}{$\begin{array}{l}\text { Ginsberg, } 1996 \\
\text { Belgium }\end{array}$} & ACR & 24 & $\begin{array}{l}\text { Amitriptyline } \\
\text { (25 mg qhs) }\end{array}$ & Parallel & $46( \pm 12)$ \\
\hline & & 22 & Placebo & 8 weeks & 83 \\
\hline \multirow[t]{2}{*}{$\begin{array}{l}\text { Goldenberg, } 1996 \\
\text { USA }\end{array}$} & ACR & 31 & $\begin{array}{l}\text { Amitriptyline } \\
\text { (25 mg) }\end{array}$ & Crossover & $43.2( \pm 9.1)$ \\
\hline & & & $\begin{array}{l}\text { Fluoxetine (20 mg) } \\
\text { Amitriptyline }+ \\
\text { Fluoxetine }\end{array}$ & $\begin{array}{l}6 \text { weeks each with } \\
2 \text {-week washouts }\end{array}$ & 90 \\
\hline
\end{tabular}

(Continued)

treatment, demographics, study design, and outcomes measured, we felt that quantitative pooling was appropriate to determine an overall effect of antidepressants for the various symptoms of fibromyalgia. Among the 13 trials with extractable data, 2 involved multiple arms comparing selective serotonin reuptake inhibitors (SSRIs), tricyclic anti- 
Table 1. (Continued)

\begin{tabular}{|c|c|c|c|c|c|}
\hline $\begin{array}{l}\text { Study, Year, } \\
\text { Country }\end{array}$ & $\begin{array}{l}\text { Inclusion } \\
\text { Criteria }\end{array}$ & $N$ & $\begin{array}{l}\text { Treatment } \\
\text { Groups }\end{array}$ & $\begin{array}{l}\text { Design } \\
\text { Duration }\end{array}$ & $\begin{array}{l}\text { Mean Age } \\
\text { (SD or range) } \\
\% \text { Women }\end{array}$ \\
\hline & & 6 & Amitriptyline & 8 weeks & 100 \\
\hline & & 8 & Placebo & & \\
\hline & & 32 & Amitriptyline & & 100 \\
\hline & & 30 & Placebo & 12 weeks & \\
\hline \multirow[t]{2}{*}{ Olin, 1998} & ACR & 24 & Ritanserin & Parallel & $44(24-59)$ \\
\hline & & 27 & Placebo & 16 weeks & 100 \\
\hline
\end{tabular}

* Smythe criteria: $\geq 3$ months of widespread pain; 12 of 14 specific tender points; and sleep disturbance.

${ }^{\dagger}$ American College of Rheumatology criteria: $\geq 3$ months of widespread pain; and 11 of 18 specific tender points.

${ }^{\ddagger}$ Minor criteria for Goldenberg and Tavoni study: modulation of symptoms with activity, weather, anxiety, or stress; sleep disturbance; tiredness; chronic headaches; irritable bowel syndrome; subjective swelling; and numbness.

All studies excluded patients with repetitive trauma or a systemic condition.

depressants, and placebo: amitriptyline versus fluoxetine ${ }^{23}$ and clomipramine versus maprotiline. ${ }^{21}$ Hence, a total of 15 different drug arms are included in this meta-analysis. The majority of arms (10 of 15) studied tricyclic antidepressants. Three tricyclic antidepressants were studied: amitriptyline in 8, and clomipramine and maprotiline in 1 each. Two trials used S-adenosylmethionine and 3 studied SSRIs (fluoxetine- 2 trials, citalopram-1 trial, Table 1).

\section{Quantitative Synthesis}

Dichotomous outcome data were extractable from 10 of the articles. The dichotomous outcome effect sizes were homogeneous $\left(\chi^{2}=12.49, d f=11 ; P=.33\right)$ and demonstrated evidence of publication bias $(P=.04)$. The resulting odds ratio for improvement with therapy was 4.2 (95\% CI, 2.6 to 6.8; Figure 1). In order to quantify the clinical significance of the intervention in terms of number needed to treat (NNT) to improve the symptoms of 1 patient, we determined the pooled risk difference $(0.25 ; 95 \%$ CI, 0.16 to 0.34$)$. This risk difference translates into an NNT of 4 (95\% CI, 2.9 to 6.3). In other words, 4 individuals would need treatment for 1 patient to experience symptom improvement.

Continuous outcomes were extractable from 10 trials. Five different continuous outcomes were extracted: the number of trigger points and pain scores from 10 trials, sleep and fatigue scores from 8 , and overall well-being from 7. On tests for heterogeneity, pain severity $\left(\chi^{2}=22.0, d f=\right.$ $9 ; P=.009)$, fatigue $\left(\chi^{2}=14.2, d f=8 ; P=.08\right)$, and wellbeing $\left(\chi^{2}=15.5, d f=7 ; P=.03\right.$ ) effect sizes were found to be heterogeneous, while sleep $\left(\chi^{2}=4.9, d f=8 ; P=.8\right)$ and trigger points $\left(\chi^{2}=15.2, d f=10 ; P=.12\right)$ effect sizes were homogeneous (Figure 2). For more conservative estimates of summary effect given heterogeneity on 3 of the 5 continuous outcomes effect sizes, we synthesized data on all outcomes using a more conservative random effects model. The number of trigger points improved 0.17 standard devia- tion units (95\% CI, -0.07 to 0.42 ); fatigue scores improved 0.39 standard deviation units (95\% CI, 0.11 to 0.66); sleep scores improved 0.49 standard deviation units (95\% CI, 0.3 to 0.69); overall well-being scores improved 0.49 standard deviation units (95\% CI, 0.18 to 0.80); and pain scores improved 0.52 standard deviation units $(95 \% \mathrm{CI}, 0.21$ to 0.81). Using only the studies with similar rating scales, continuous data were combined using the original units (Table 3). This showed substantial relative improvement in each of the individual symptoms. None of the pooled continuous outcomes data indicated evidence of publication bias.

\section{Assessment of Depression}

Most of the studies systematically assessed for depression using validated instruments (Figure 2). ${ }^{15,21-27,29}$ However, only 5 of the 13 studies with extractable data report an analysis of a correlation between treatment effect and change in depression scores. ${ }^{15,23,24,26,27}$ Of these, only 1 reported a correlation. ${ }^{27}$ Thus, it cannot be determined from these studies whether any effect demonstrated is independent of an effect on depression.

\section{Sensitivity Analysis}

The findings were not overly influenced by any particular study, with the odds ratio varying from 3.2 to 4.9 and the summary mean difference from 0.7 to 1.1 standard deviation units with the sequential exclusion of individual studies from the analysis. Meta-regression showed no significant effect of year of publication $(P=.52)$, study design $(P=.65)$, study quality scores $(P=.22)$, or drug class $(P=.43)$.

\section{DISCUSSION}

Meta-analysis of these 13 published, good quality, randomized, placebo-controlled trials suggests that antidepres- 
Table 2. Quality Scores, Drug Side Effects, and Assessment of Depression for 13 Trials Included in the Meta-analysis

\begin{tabular}{|c|c|c|c|c|}
\hline Carrette, 1986 & 6 & Randomization scheme not stated & $\begin{array}{l}\text { Drowsiness and dry } \\
\text { mouth (not } \\
\text { quantified) }\end{array}$ & None \\
\hline Bibolotti, 1986 & 5 & $\begin{array}{l}\text { Randomization scheme not stated } \\
\text { No method of assessing adverse effects } \\
\text { Large loss to follow-up (51\%) }\end{array}$ & $\begin{array}{l}\text { Gastrointestinal, } \\
\text { asthenia, headache, } \\
\text { vertigo, tachycardia } \\
\text { (\% not given) }\end{array}$ & $\begin{array}{l}\text { HDRS } \\
\text { No analysis between } \\
\text { symptoms and } \\
\text { depression response }\end{array}$ \\
\hline Tavoni, 1987 & 1 & $\begin{array}{l}\text { Randomization scheme not stated } \\
\text { Effectiveness of blinding not clear } \\
\text { No description of withdrawals } \\
\text { No description of exclusion criteria } \\
\text { No method to assess adverse effects }\end{array}$ & Not assessed & $\begin{array}{l}\text { HDRS } \\
\text { "Good correlation" between } \\
\text { depression scores and } \\
\text { trigger points }\end{array}$ \\
\hline Scudds, 1989 & 4 & $\begin{array}{l}\text { Randomization scheme not described } \\
\text { Inclusion criteria not defined } \\
\text { No method to assess adverse effects }\end{array}$ & Not assessed & None \\
\hline Carrette, 1994 & 5 & $\begin{array}{l}\text { Effectiveness of blinding not clear } \\
\text { Large losses to follow-up (25\%) }\end{array}$ & $\begin{array}{l}\text { Somnolence ( } 5 \% \text { active, } \\
2.4 \% \text { placebo) }\end{array}$ & $\begin{array}{l}\text { MMPI, AIMS } \\
\text { No correlation between } \\
\text { symptom and depression } \\
\text { response }\end{array}$ \\
\hline Wolfe, 1994 & 4 & $\begin{array}{l}\text { Randomization scheme not stated } \\
\text { Effectiveness of blinding not clear } \\
\text { No intention-to-treat analysis } \\
\text { ( } 12 \% \text { follow up losses) } \\
\text { Large losses to follow-up (43\%) }\end{array}$ & $\begin{array}{l}\text { Nausea ( } 29 \% \text { active, } \\
33 \% \text { placebo); } \\
\text { headache }(9 \% \text { active, } \\
0 \% \text { placebo) }\end{array}$ & $\begin{array}{l}\text { BDI, AIMS } \\
\text { No correlation }\end{array}$ \\
\hline Carrette, 1995 & 7 & $\begin{array}{l}\text { Method of assessing adverse effects } \\
\text { not described }\end{array}$ & Not assessed & None \\
\hline Goldenberg, 1996 & 8 & & Not reported & $\begin{array}{l}\text { BDI, HDRS } \\
\text { No correlation }\end{array}$ \\
\hline Kempenaers, 1994 & 7 & $\begin{array}{l}\text { Randomization scheme not stated } \\
\text { Large losses to follow-up (35\%) } \\
\text { No intention-to-treat analysis }\end{array}$ & Not reported & $\begin{array}{l}\text { Research Diagnostic Criteria } \\
\text { Not assessed }\end{array}$ \\
\hline Hannonen, 1998 & 8 & $\begin{array}{l}\text { Large losses to follow-up (29\%) } \\
\text { No intention-to-treat analysis }\end{array}$ & Not reported & $\begin{array}{l}\text { Scid-Ro (depressed patients } \\
\text { excluded) }\end{array}$ \\
\hline
\end{tabular}

HDRS indicates Hamilton Depression Rating Scale; BDI, Beck Depression Inventory; MMPI, Minnesota Multiphasic Personality Inventory; AIMS, Arthritis Impact Measurement Scale; SCID-Ro, Structured Clinical Interview for DSM III-R disorders.

sants reduce the symptoms of fibromyalgia. While most individual studies were not individually statistically significant, all published results graphically fell on the side of effectiveness and pooled results showed a significant benefit of antidepressants. On meta-regression, there was no variable or study which had a significant independent effect on the overall effect size, thereby minimizing what few qualitative differences there were in these studies.

The probability of benefit is clinically appealing. Patients treated with antidepressants were more than four times as likely to improve. From a different analysis, using pooling of the risk difference, the number needed to treat was 4 ; in other words, 4 individuals would need treatment with antidepressants to improve 1 patient's symptoms.

The magnitude of benefit also appeared clinically significant. Study patients experienced a range of improvement in various symptoms of fibromyalgia, from 0.2 standard deviation units improvement in the number of trigger points to over one-half standard deviation improvement in average pain scores. To put this finding into context, effect sizes of 


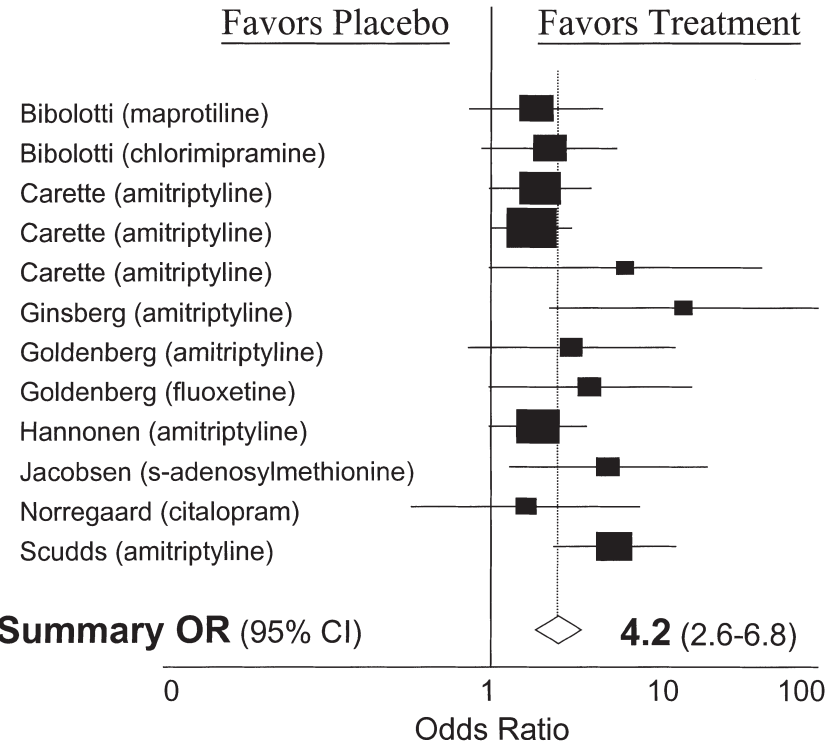

FIGURE 1. Individual study and summary effect size on the dichotomous outcome of "improvement." OR indicates odds ratio; $\mathrm{Cl}$, confidence interval.

$0.2,0.5$, and 0.8 standard deviations are commonly considered mild, moderate, and large treatment effects. ${ }^{31}$ When original units could be combined, there was evidence of substantial relative improvement: from $9 \%$ fewer trigger points to $26 \%$ less pain. Therefore, the symptomatic benefits of antidepressants appear to be mild for fatigue and number of trigger points, and moderate for sleep, overall well-being, and pain severity. Of the 5 continuous measures of fibromyalgia symptoms, only the number of trigger points was not statistically improved.

Although the syndrome of fibromyalgia is well described, its etiology and pathophysiology are poorly understood. ${ }^{32-34}$ There is some evidence that patients with fibromyalgia have a heightened pain response, ${ }^{35-37}$ as well as abnormal sleep patterns. ${ }^{38-41}$ Neurohormonal abnormalities, physical or emotional trauma, psychological stress, and infectious causes have also been postulated, although no single etiologic factor has been identified. ${ }^{2}$ Thus, there may be several mechanisms by which antidepressants improve fibromyalgia symptoms, such as pain control, mood

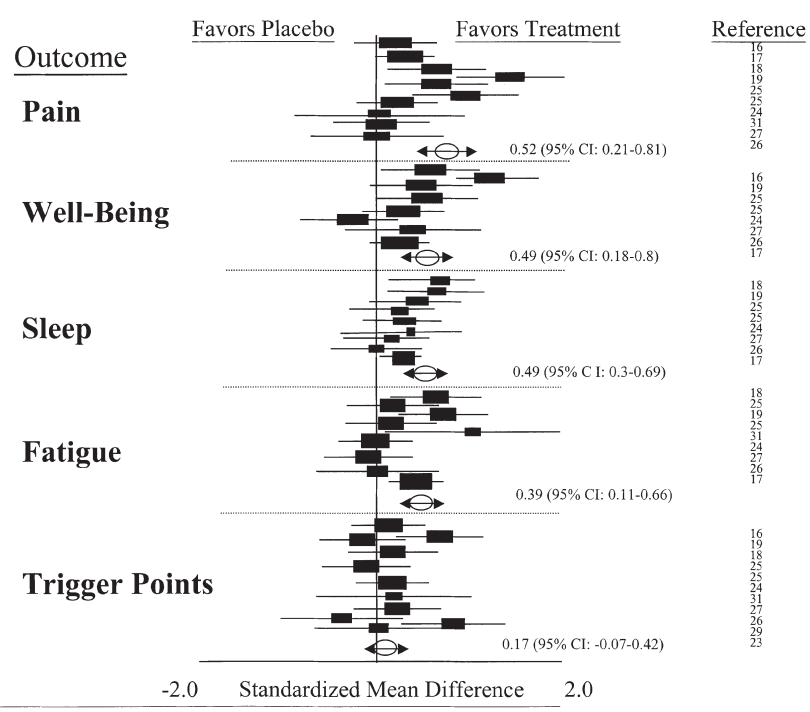

FIGURE 2. Individual study and summary effect size on multiple continuous outcomes: pain, well-being, sleep, fatigue, and trigger points. $\mathrm{Cl}$ indicates confidence interval.

stabilization, and improved sleep. Disturbed sleep is particularly interesting, as this may be both a causative factor as well as a symptom of disease. If abnormal sleep precedes the development of fibromyalgia, the effect of antidepressants may be primarily associated with improved sleep.

Traditional methods of pain control such as nonsteroidal anti-inflammatory medications (NSAIDs), while the mainstay of treatment for degenerative and inflammatory musculoskeletal disorders, have not been very effective in the treatment of fibromyalgia. Several studies have compared NSAIDS to tricyclics and have found no benefit in symptoms with NSAIDs alone, and no synergy when used with antidepressants. ${ }^{2,18}$

Only 3 of the trials assessed the effectiveness of SSRIs on fibromyalgia. ${ }^{23-25}$ While we found no difference in the efficacy of SSRIs and the other drug classes studied, the small sample size of studies makes it difficult to assess relative efficacy. Other meta-analysis of the efficacy of SSRIs for symptoms have included headache, ${ }^{42}$ and psychogenic pain. ${ }^{43}$ These also found no differences between

Table 3. Relative Improvement of Individual Fibromyalgia Symptoms Associated with Antidepressants in Studies Using Similar Rating Scales*

\begin{tabular}{lccr}
\hline \hline Symptom & $\begin{array}{c}\text { Treatment Mean } \\
\text { (95\% Confidence Interval) }\end{array}$ & $\begin{array}{c}\text { Placebo Mean } \\
\text { (95\% Confidence Interval) }\end{array}$ & $\begin{array}{r}\text { Relative Improvement } \\
\%\end{array}$ \\
\hline Fatigue & $5.0(2.7$ to 7.3$)$ & $5.8(4.5$ to 7.3$)$ & 14 \\
Trigger points & $10.6(6.5$ to 14.8$)$ & $11.6(7.2$ to 16.1$)$ & 9 \\
Pain & $4.3(2.8$ to 5.8$)$ & $5.8(3.8$ to 7.8$)$ & 26 \\
Sleep & $5.0(3.2$ to 6.9$)$ & $6.5(4.7$ to 8.2$)$ & 23 \\
Well-being & $5.2(3.6$ to 6.7$)$ & $6.5(5.0$ to 7.9$)$ & 18 \\
\hline
\end{tabular}

*Data included in this table are only from studies that had similar rating scales (e.g., visual analog scales from 0-10 or 0-100). Data was combined using the DerSimonian and Laird random effects model. 
tricyclic antidepressants and SSRIs, although these metaanalyses were also hampered by the paucity of trials using SSRIs. One large meta-analysis evaluating antidepressant effectiveness in chronic, unexplained pain found tricyclic antidepressant studies to be more likely to show benefit than SSRIs. ${ }^{44}$ Tricyclics have been found to be more effective than SSRIs in treatment of neuropathic pain. ${ }^{9}$ One of the trials in this review found that the combination of tricyclics with SSRIs was more effective than either alone. ${ }^{23}$ Well-designed, randomized, controlled trials are needed to assess the relative efficacy of different classes of antidepressants in fibromyalgia.

Does responsiveness to antidepressants then imply that psychological factors also play a role in fibromyalgia? There have been numerous studies demonstrating that patients with underlying psychological disorders are more likely to seek medical care for their symptoms. ${ }^{45-47}$ In addition, patients with depressive or anxiety disorders tend to rate their physical symptoms as more severe. ${ }^{45-47}$ Most trials $(10 / 13)$ in our review included some baseline measure of psychological disorders. The Beck Depression Inventory or Hamilton Rating Scale were the tools used most frequently in reporting depressive symptoms in study subjects. However, this assessment was only included in the analysis of 5 trials. ${ }^{15,23,24,26,27}$ Four of the 5 trials which did do such an analysis found no relationship between improvement of fibromyalgia symptoms and change in the depression scores. ${ }^{15,23,24,26}$ Since most studies treated patients with subtherapeutic doses of antidepressants and for relatively short duration, it seems unlikely that the benefit is entirely due to antidepressant properties of these drugs. However, without fully controlling for the effects of antidepressants on psychological disorders, it is impossible to know if the efficacy observed with antidepressants in fibromyalgia is mediated through or independent of an effect on depression.

This literature has several limitations. One limitation, common to many studies, was the question of adequate blinding. Most studies either reported no measure of blinding or provided evidence that adequate blinding was not achieved (Table 2). Given the side effect profile of antidepressants it is easy to understand how blinding would be difficult to attain, regardless of the use of identical placebos. Inadequate blinding in previous randomized trials has led to erroneous conclusions regarding treatment, such as vitamin C's benefits for the common cold. ${ }^{48,49}$

A second limitation is that included studies were relatively short in duration, only 8.7 weeks. This is a particular concern in a syndrome such as fibromyalgia that tends to have a chronic course. The short duration of study treatment limits the ability to know whether the benefit will persist over time, or what the optimal duration of treatment should be.

Despite these limitations, our analysis suggests that antidepressants are effective in fibromyalgia. Physicians can expect to see improvement in 1 patient for every 4 treated, with over one-half standard deviation of improve- ment in pain severity. The myriad facets of fibromyalgia appear to be generally improved with the use of antidepressants. Further research is needed to assess the relative efficacy of different classes of antidepressants, as well as whether such efficacy is independent of an effect on depression.

Supported by a grant from the MacArthur Foundation Initiative on Depression in Primary Care (PGO).

\section{REFERENCES}

1. Wolfe F. Fibromyalgia, the clinical syndrome. Rheum Dis Clin NA. 1989;15:1-17.

2. Goldenberg DL. Fibromyalgia syndrome a decade later: what have we learned?. Arch Intern Med. 1999;159:777-85.

3. Hudson JL, Goldenberg DL, Pope HG Jr, Keck PE Jr, Schlesinger L. Comorbidity of fibromyalgia with medical and psychiatric disorders. Am J Med. 1992;92:363-7.

4. Triadafilopoulos G, Simms RW, Goldenberg DL. Bowel dysfunction in fibromyalgia syndrome. Dig Dis Sci. 1991;36:59-64.

5. Ahles TA, Khan SA, Yunus MB, Spiegell DA, Masi AT. Psychiatric status of patients with primary fibromyalgia, patients with rheumatoid arthritis and subjects without pain: a blind comparison of DSM-III diagnoses. Am J Psychiatry. 1991;148:1721-6.

6. Yunus MB, Ahles TA, Aldag JA, Masi AT. Relationships of clinical features with psychological status in primary fibromyalgia. Arthritis Rheum. 1991;34:15-21.

7. Onghena P, Van Houdenhove B. Antidepressant-induced analgesia in chronic non-malignant pain: a meta-analysis of 39 placebocontrolled studies. Pain. 1992;49:205-19.

8. McQuay HJ, Tramer M, Nye BA, Carroll D, Wiffen PJ, Moore RA. A systematic review of antidepressants in neuropathic pain. Pain. 1996;68:217-27.

9. Jung AC, Staiger T, Sullivan M. The efficacy of selective serotonin reuptake inhibitors for the management of chronic pain. J Gen Intern Med. 1997;12:384-9.

10. The Cochrane Collaboration. The Cochrane Library. Oxford, United Kingdom: Update Software; 1999 (updates quarterly).

11. Jadad AR, Moore RA, Carroll D, et al. Assessing the quality of reports of randomized clinical trials: is blinding necessary? Control Clin Trials. 1996;17:1-12.

12. Egger M, Smith GD, Schneider M, Minder C. Bias in meta-analysis detected by a simple, graphical test. BMJ. 1997;315:629-34.

13. DerSimonian R, Laird N. Meta-analysis in clinical trials. Control Clin Trials 1986;7:177-88.

14. Carrette S, McCain GA, Bell DA, Fam AG. Evaluation of amitriptyline in primary fibrositis. A double-blind placebo-controlled study. Arthritis Rheum. 1986;29:655-9.

15. Carrette S, Bell MJ, Reynolds WJ, et al. Comparison of amitriptyline, cyclobenzaprine, and placbo in the treatment of fibromyalgia. A randomized double blind clinical trial. Arthritis Rheum. 1994;1:32-40.

16. Carrette S, Oakson G, Guimont C, Steriade M. Sleep electroencephalography and the clinical response to amitriptyline in patients with fibromyalgia. Arthritis Rheum. 1995;38:1211-7.

17. Ginsberg F, Mancaux A, Joos E, Vanhove P, Famaey JP. A randomized placebo-controlled trial of sustained-release amitriptyline in primary fibromyalgia. J Musculoskeletal Pain. 1996;4:37-47.

18. Goldenberg DL, Felson DT, Dinerman H. A randomized, controlled trial of amitriptyline and naproxen in the treatment of patients with fibromyalgia. Arthritis Rheum. 1986;29:1371-7.

19. Jaeschke R, Adachi J, Guyatt G, Keller J, Wong B. Clinical usefulness of amitriptyline in fibromyalgia: the results of $23 \mathrm{~N}-$ of- 1 randomized controlled trials. J Rheumatol. 1991;18:447-51.

20. Scudds RA, McCain GA, Rollman GB, Harth M. Improvements in 
pain responsiveness in patients with fibrosists after successful treatment with amitriptyline. J Rheumatol. 1989;16:98-103.

21. Bibolotti E, Borghi C, Pasculli E, et al. A double-blind comparison of maprotiline and placebo. Clin Trials J. 1986;23:269-80.

22. Hannonen P, Malminiemi K, Yli-Kerttula U, Isomeri R, Roponen P. A randomized, double-blind, placebo-controlled study of moclobemide and amitriptyline in the treatment of fibromyalgia in females without psychiatric disorder. Br J Rheumatol. 1998;37:1279-86.

23. Goldenberg D, Mayskiy M, Mossey C, Ruthazer R, Schmid C. A randomized, double-blind, crossover trial of fluoxetine and amitriptyline in the treatment of fibromyalgia. Arthitis Rheum. 1996; 39:1852-9.

24. Wolfe F, Cathey MA, Hawley DJ. A double-blind placebo controlled trial of fluoxetine in fibromyalgia. Scand J Rheumatol. 1994; 23:255-9.

25. Norregaard J, Volkmann H, Danneskiold-Samsoe B. A randomized controlled trial of citalopram in the treatment of fibromyalgia. Pain. 1995;61:445-9.

26. Jacobsen S, Danneskiold-Samsoe B, Bach Andersen R. Oral S-adenosylmethionine in primary fibromyalgia. Double-blind clinical evaluation. Scand J Rheumatol. 1991;20:294-302.

27. Tavoni A, Vitali C, Bombardieri S, Pasero G. Evaluation of s-adenosylmethionine in primary fibromyalgia: a double-blind crossover study. Am J Med. 1987;83(suppl 5A):107-10.

28. Olin R, Klein R, Berg PA. A randomised double-blind 16-week study of ritanserin in fibromyalgia syndrome: clinical outcome and analysis of autoantibodies to serotonin, gangliosides, and phospholipids. Clin Rheumatol. 1998;17:89-94.

29. Kempenears CH, Simenon G, Vander Elst M, Fransolet L, Mingard $\mathrm{P}$, de Maertelaer V. Effect of an antidiencephalon immune serum on pain and sleep in primary fibromyalgia. Neuropsychobiology. 1994; 30:66-72.

30. Wolfe F, Smythe HA, Yunus MB, et al. The American College of Rheumatology 1990 criteria for the classification of fibromyalgia: report of the multicenter criteria committee. Arthritis Rheum. 1990;33:160-72.

31. Cohen J. Statistical power analysis for the behavioral sciences. New York, NY: Academic Press; 1969.

32. Yunus MD, Kalayan-Raman UP, Masi AT, Aldag AT. Electromicroscopic studies of muscle biopsy in primary fibromyalgia syndrome: a controlled and blinded study. J Rheumatol. 1989; 16:97-101.

33. Simms RW, Roy SH, Hrovat M, et al. Lack of association between fibromyalgia syndrome and abnormalities and muscle energy metabolism. Arthritis Rheum. 1994;37:794-800.
34. Pillemer SR, Bradley LA, Crofford LJ, Moldofsky H, Chrousos GP. The neuroscience and endocrinology of fibromyalgia. Arthritis Rheum. 1997;40:1928-39.

35. Arroyo JF, Cohen ML. Abnormal responses to electrocutaneous stimulation in fibromyalgia. J Rheumatol. 1993;20:1925-31.

36. Kosek E, Ekholm J, Hansson P. Increased pressure pain sensibility in fibromyalgia patients is located deep in the skin but not restricted to muscle tissue. Pain. 1995;63:335-9.

37. Kosek E, Ekholm J, Hansson P. Modulation of pressure pain thresholds during and following isometric contraction in patients with fibromyalgia and in healthy controls. Pain. 1996;64:415-23.

38. Drewes AM, Gade J, Nielsen KD, Bjerregard K, Taaghholt SJ, Svendsen L. Clustering of sleep electroencephalographic patterns in patients with the fibromyalgia syndrome. Arthritis Rheum. 1992;335:1151-6.

39. May KP, West SG, Baker MR, Everett DW. Sleep apnea in male patients with the fibromyalgia syndrome. Am J Med. 1993;94:505-8.

40. Yunus MB, Aldag JC. Restless leg syndrome and leg cramps in fibromyalgia syndrome: a controlled study. BMJ. 1996;312:1339.

41. MacFarlane JG, Shahal B, Mously C, Moldofsky H. Periodic $\mathrm{K}$-alpha sleep EEG activity and periodic limb movements during sleep: comparisons of clinical features and sleep parameters. Sleep. 1996;19:200-4.

42. Tomkins GE, Jackson JL, O’Malley PG, Kroenke K, Balden E, Santoro JA. Treatment of chronic headache with anti-depressants: a meta-analysis. J Gen Intern Med. 1999;14(suppl 2):75.

43. Fishbain DA, Cutler RB, Rosomoff HL, Rosomoff RS. Do antidepressants have an analgesic effect in psychogenic pain and somatoform pain disorder? A meta-analysis. Psychosom Med. 1998;60:503-9.

44. O'Malley PG, Jackson JL, Tomkins GE, Santoro JA, Balden E, Kroenke K. Efficacy of antidepressants for physical symptoms: a critical review. J Fam Pract. 1999;48:980-90.

45. Katon W, Kleinman A, Rosen G. Depression and somatization: a review. Am J Med. 1982;72:127-5, 241-7.

46. Kroenke K, Spitzer RL, Williams JBW, et al. Physical symptoms in primary care: predictors of psychiatric disorders and functional impairment. Arch Fam Med. 1994;3:774-9.

47. Smith GR. The epidemiology and treatment of depression when it coexists with somatoform disorders, somatization, or pain. Gen Hosp Psychiatry. 1992;14:265-72.

48. Max MB. Treatment of post-herpetic neuralgia: antidepressants. Ann Neurol 1994;35(suppl):S50-3.

49. Chalmers TC. Effects of ascorbic acid on the common cold. Am J Med. 1973;58:532-6. 